This document is the accepted manuscript version of the following article:

Semančíková, E., Grădinaru, S. R., Aubrechtová, T., \& Hersperger, A. M. (2020). Framing fragmentation in strategic policy documents in spatial planning and environmental domains: differences and similarities. Journal of Environmental Planning and Management, 63(3), 415-432.

https://doi .org/10.1080/09640568.2019.1589433

\title{
Framing fragmentation in strategic policy documents of spatial planning and environmental domains: differences and similarities
}

\begin{abstract}
:
Fragmentation is a complex issue and the way it is framed will impact policy decisions. The Czech Republic has adopted several strategic policy documents in spatial planning and environmental domains that address fragmentation. However, these documents differ in how they frame fragmentation. Our goal was to evaluate the differences in 1) framing the problem of fragmentation and 2) suggested solutions. We performed a content analysis of the strategic policy documents by coding text using the key fragmentation aspects - biological organization, land cover, and connectivity. Next, we categorized data either to species-oriented, pattern-oriented, or ecosystem service frames and suggested criteria to evaluate the quality of the framing. This method was useful to show the divergences in the framing of fragmentation as a problem between two policy domains. The results show that the pattern oriented frame and mitigation solutions are the most prominent aspects, and also fragmentation is not well framed.
\end{abstract}

Keywords: habitat fragmentation, landscape fragmentation, problem framing, policy domain, planning 


\section{Introduction}

Fragmentation is a hierarchically nested and cross-cutting landscape process occurring at various spatial and temporal scales. Many biological and ecological studies focus on the fragmentation process because it is seen as the chief threat to biodiversity, ecosystem functions and services (Resasco et al., 2017). Fragmentation is a typical example of a complex environmental issue that allows for many perspectives and interpretations (see reviews of Fahrig, 2003; Hadley and Betts, 2016; Haila, 2002; Lindenmayer and Fischer, 2007; Mitchell et al., 2015). It has been misused as an umbrella term for human derived processes negatively altering landscapes (Lindenmayer and Fischer, 2007). In fact, the concept has been applied so broadly (Haila, 2002) that the term is now often used as an axiom with no clear definition (Hadley and Betts, 2016).

The concept of "fragmentation" is derived from the Latin word "fragmentum", which means a broken piece, remnant or fragment. It is a physical process of breaking apart land cover patches per see (of either habitat or different vegetation types), where the remaining patches vary in configuration and their connectivity is altered (Fahrig, 2003; Hadley and Betts, 2016). The process of fragmentation has to be differentiated from habitat loss because the consequences are different (Fahrig, 2003; Fischer and Lindenmayer, 2007; Hadley and Betts, 2016; Lindenmayer and Fischer, 2007). The consequences may be either negative or positive if assessed from the perspective of a single species (either animal or plant species), species assemblage or humans (Fahrig, 2017; Mitchell et al., 2015). Clearly, both the broad use of the term fragmentation to refer to various processes altering landscapes, as well as its use to refer to habitat loss, are false interpretations.

In the public policy realm, fragmentation has to be framed as a policy problem to ensure effective, strategic and long term planned solutions to its consequences (Bennet and Saunders, 2010; Jaeger and Madrinan, 2011; Secretariat of the CBD, 2005). Problem framing 
entails the process of telling a story about the environmental conditions that might cause a problem, what should be done about it, and determine the responsibility of various actors (Karlsson-Vinkhuyzen et al., 2017; Nisbet, 2009). The way public institutions frame fragmentation further influences decisions about its integration into the policy agenda, selection of policy instruments to address it (e.g. adoption of legislation, allocation of financial tools), as well as the setting of solutions and responsibilities (Ebbin, 2011; Haug et al., 2010; Loomis et al., 2003).

Institutions from various policy domains frame policy problems differently because they adhere to different values, have other interests and work with different types of information, which may finally influence their perspective about fragmentation. In consequence, institutions provide various formal frames that can be identified in written policy documents they adopt (Moschitz, 2018). Solutions to address fragmentation may differ according to how fragmentation is framed as a problem by the various institutions. Thus, it is important to know how policy documents frame fragmentation as a problem.

Spatial planning and environmental policies are the most appropriate for addressing fragmentation because they may directly define and support practices to prevent fragmentation, improve connectivity of fragmented land cover, and identify areas that should be protected against fragmentation (Kettunen et al., 2007). Strategic spatial planning and environmental policy documents are of interest because they provide the frames for policies on lower levels (Loorbach, 2010), formulate statements and define strategic policy solutions for the prevention of unexpected and undesirable future events (Daugbjerg et al., 2009; Veselý and Nekola, 2007). To address the pressing effects of fragmentation with policies, they should propose region-specific solutions (Haila, 2002), which are adapted to the magnitude of fragmentation (McIntyre and Hobbs, 1999), focus on the protection of nonfragmented areas, connectivity restoration and fragmentation monitoring (Jaeger and 
Madrinan, 2011). So far, the importance of framing fragmentation in strategic policy documents for the formulation of appropriate solutions has been poorly explored.

The Czech Republic is suitable for studying how fragmentation has been framed in policy documents. Since the country joined the EU in 2004, increasing attention has been paid to the process of fragmentation in the context of European environmental policy. Several strategic environmental and spatial planning policy documents were adopted at the national and regional levels in order to define the problem and propose solutions to the various environmental issues directly linked to fragmentation (Semančíková et al., 2008). Despite policy integration advancements, fragmentation remains an important issue, as half of the country's total area is highly fragmented compared to other European regions, i.e. the effective mesh density in most Czech NUTS 3 regions is above 20 meshes per $1000 \mathrm{~km}^{2}$ (EEA, 2011). A further decline of $11 \%$ in the so far non-fragmented areas is expected by 2040 (CENIA, 2013).

The aim of this study was to determine how these strategic environmental and spatial planning documents frame fragmentation, using the Czech Republic as an example. We thus addressed the following questions:

- What are the differences and similarities in framing fragmentation in the strategic documents within the spatial planning and environmental policy domains?

- What types of solutions are promoted by the spatial planning and environmental policy domains?

To answer these questions, we used content analysis of policy documents adopted within the two policy domains. In section two, we present a theoretical framework for assessing fragmentation framing; in section three we present the methodology used in the 
analysis; the results are given in section four; in section five we discuss the challenges of framing fragmentation; and section six provides final conclusions.

\subsection{Theoretical framework for assessing fragmentation-framing}

In the text below we propose a theoretical framework for assessing frames by building on previous studies by Lindenmayer and Fischer (2007), Fischer and Lindenmayer (2007), and Mitchell (2015). We propose three different frames of fragmentation: a species-oriented frame, a pattern oriented frame and an ecosystem-service frame (Figure 1). These three frames represent a unique combination of 1) knowledge and values, 2) perspective on humans and/or species, and 3) focus on fragmentation aspects (Figure 1). The various frames emerge depending on the amount and type of knowledge and values, and seeing the key fragmentation aspects from different perspectives.

The knowledge and values represent framing elements that influence the various perspectives on fragmentation aspects (Figure 5). These two elements were proposed by Knaggård (2015) as key ingredients of problem framing and are used here to address the quality of framing. Knowledge, i.e. knowledge about the state of the problem and identification of its causes, is seen as the most important element for framing (Bardwell, 1991; Knaggård, 2015) and for decision makers to decide on solutions (Michaels, 2009). In the context of framing fragmentation as a policy problem, knowledge comes from scientific research or personal or institutional experience about, for example, the type, magnitude and causes of fragmentation and its consequences.

Values are linked to explanations regarding why we should care about a problem, what is threatened, what should be protected, and who is responsible for formulating solutions (Knaggård, 2015). Therefore, values are associated with motivations for action. In the context of framing fragmentation, values refer to the consequences related to various fragmentation 
aspects, to statements about what should be done to deal with the consequences, and the actors responsible for solutions (either people or institutions).

Values can be either eco-centric or anthropocentric (Karlsson-Vinkhuyzen et al., 2017); together with available knowledge, they are closely related to various perspectives about the fragmentation aspects which give rise to the various frames (Figure 5). Eco-centric values derive from species or human-species perspectives. The species perspective is determined from how non-human species perceive their environment, and is based on scientific knowledge related to metapopulational theory. Meanwhile, the human-species perspective is based on human suggestions about species needs, and it is based on scientific knowledge related to island/biogeographic theory. Anthropocentric values derive from a purely human-centered perspective, which focuses solely on human needs. Therefore, this perspective is closely related to the ecosystem services concept.

Biological organization, land cover, and connectivity are the key aspects influenced by fragmentation (Lindenmayer and Fischer 2007; Fischer and Lindenmayer 2007); how these aspects are presented depends on the knowledge, values and perspectives of different people or institutions. Biological organization refers to a single species, a species assemblage or humans (Lindenmayer and Fischer, 2007; Mitchell et al., 2015). Their dispersal, abundance, richness, or even extinction events are influenced by the size, connectivity and also quality of land cover patches (Deák et al., 2018; Donaldson et al., 2017). We distinguish two types of land cover: 1) "habitat" which is an area of suitable living conditions and resources for a single species, and has to be differentiated from 2) vegetation types delineated based on the composition of either native or human modified vegetation (Hadley and Betts, 2016). For the purposes of this paper, we call this latter type "human designated patches of land cover". If fragmentation is understood as being the process of breaking apart patches of land cover per se, independent of their loss, then the former type of land cover "habitat" refers to the concept 
of habitat fragmentation, while the latter "human designated patches of land cover" refers to the concept of landscape fragmentation, i.e. the human perception of fragmentation and degradation of natural or semi-natural areas (Di Giulio et al., 2009). It is important to distinguish between habitat fragmentation and fragmentation of human designated patches of land cover because some species may survive in patches of native or human modified vegetation (Lindenmayer and Fischer, 2007). The connectivity aspect refers to linkages between patches of the same or similar land cover, which may be isolated due to fragmentation. A larger degree of connectedness, both for structural and functional connectivity, increases the movement of biological organizations and counteracts biodiversity loss (Baguette and Van Dyck, 2007; Lindenmayer and Fischer, 2007). Structural connectivity entails information on the spatial configuration of human designated patches of land cover across a landscape and facilitates movement of species assemblage or humans. Nevertheless, the perception of a landscape is strongly species specific, thus we cannot provide an ultimate score for landscape fragmentation, which would be valid for all species. The level of fragmentation in a certain landscape should be evaluated on the level of different taxa or species given their strongly differing habitat preferences. Thus, functional connectivity is important as it refers to the real movement of a single species within a habitat (Uezu et al., 2005) and is generally considered to be more important than structural connectivity because it incorporates information on how organism behavior is affected by changes in landscape structure.

Different frames arise based on the knowledge, values and perspectives of the particular people or institutions involved as well as the fragmentation aspects of the habitat in question (Figure 1). The species-oriented frame is based on population biology and corresponds to knowledge regarding a species perspective of the fragmented patches of habitat cover, which provide them with resources and living conditions (Lindenmayer and 
Fischer, 2007). This frame corresponds to the functional connectivity of habitat patches and the real movement of animal or plant species in both space and time (Auffret et al., 2015; Zetterberg et al., 2010). Values, i.e. why we should care and what is threatened, are focused on the single species, habitat degradation, their sub-division, isolation, or functional connectivity. Second, the pattern-oriented frame is based on landscape ecology and corresponds to knowledge in terms of an interrelated human-species perspective on species assemblage needs in fragmented landscapes. This frame corresponds to human designated patches of native vegetation and structural connectivity. Values would focus on the spatial pattern of patches of native vegetation and their connectivity under the assumption that increased connectedness improves the living conditions for the species assemblage. The final frame, as its name suggests, is based on ecosystem services, i.e. the benefits that humans gain from the natural environment. In the context of fragmentation, this frame focuses on patches of human modified vegetation, and their connectivity by infrastructure (Mitchell et al., 2015). The aim would be to improve ecosystem services as well as human well-being and human movement through the landscape. Concepts and statements associated with the three frames are summarized in Table 1, while examples are given in chapter 2.3.

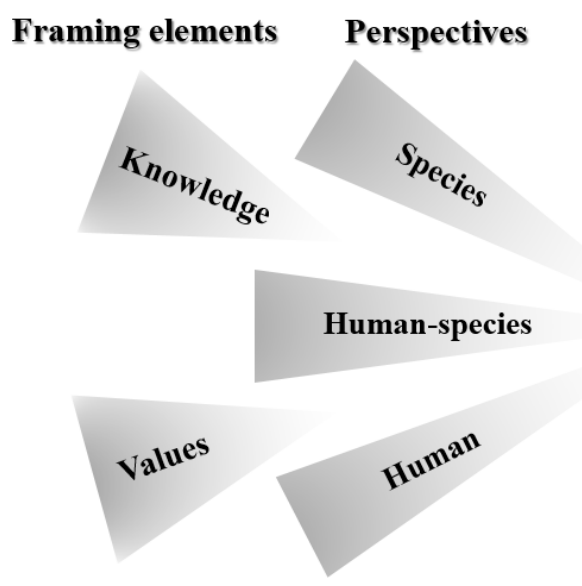

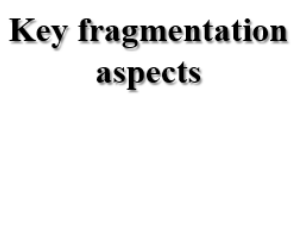

Biological organisation Land cover Connectivity

\section{Frames}

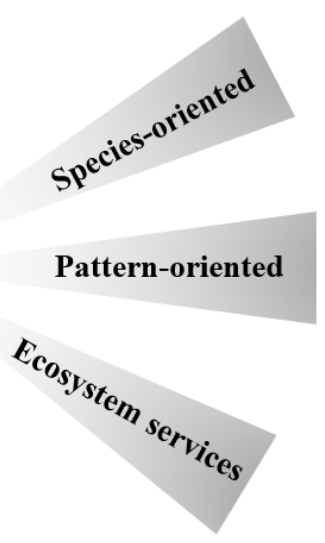


Figure 1: The key fragmentation aspects viewed from different perspectives refer to different knowledge, values and results to different frames.

\section{Methods}

The methods section is divided into four subsections: 2.1. the selection of strategic policy documents, 2.2. the content analysis of the documents, 2.3. methods to assess the differences and similarities in framing fragmentation (Question 1), and 2.4. methods to assess the types of solutions in environmental and spatial planning policy domains (Question 2).

\subsection{Selection of strategic documents in environmental and spatial planning policy domains}

To analyze the differences and similarities in how fragmentation is framed in the strategic documents of the spatial planning and environmental policy domains, we searched for strategic documents that were in force when the analysis was conducted (i.e. 2014-2015) and which addressed fragmentation. A total of 11 strategic documents were selected for analysis of the fragmentation frames, representing policy documents issued by institutions in the environmental (three documents) and spatial planning policy domains (eight documents). The documents were adopted between 2005 and 2015 (Figure 2) and represented all available national strategic documents in both policy domains and half of the Regional Development Plans (RDPs). The seven RDPs were randomly chosen out of the 14 RDPs in the Czech Republic.

The environmental policy domain documents (further referred to as environmental documents) are the National Environmental Policy (NEP), the National Strategy of Biological Diversity (NSBD), and the National Program of Nature and Landscape Protection (NPNLP). They are the most important environmental policy documents adopted at the national level in 
the Czech Republic and describe environmental quality, identify threats and provide solutions. The documents are mandatory, meaning that they are not legally binding but should be considered in the process of sectorial planning.

The documents in the spatial planning policy domain (further referred as spatial planning documents) included the National Planning Policy (NPP) (MoRD, 2015) and Regional Development Plans (RDPs). The NPP is the most important spatial planning document in the Czech Republic. In contrast to the mandatory environmental documents, the NPP provides legally binding guidelines for the RDPs, i.e. the RDPs have to be consistent with the NPP (the Parliament of the Czech Republic, 2006). The RDPs create the preconditions for regional sustainable development, specify and develop the objectives and tasks given in the NPP, determine strategies and coordinate the planning activities of municipalities on the local level. The spatial planning documents are legally binding for municipalities and land owners according to Act 183/2006 Coll. (the Parliament of the Czech Republic, 2006). Figure 6 shows the studied documents as well as their interrelations.

Environmental domain

National Environmental Policy

(NEP, 2012)

National Strategy on Biological Diversity (NSBD, 2005)

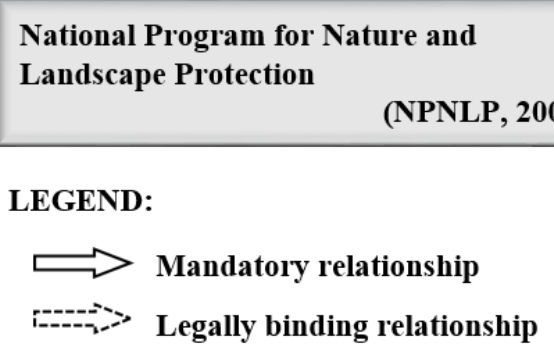

National Program for Nature and Landscape Protection
Spatial planning domain

National Planning Policy

(NPP, 2015)
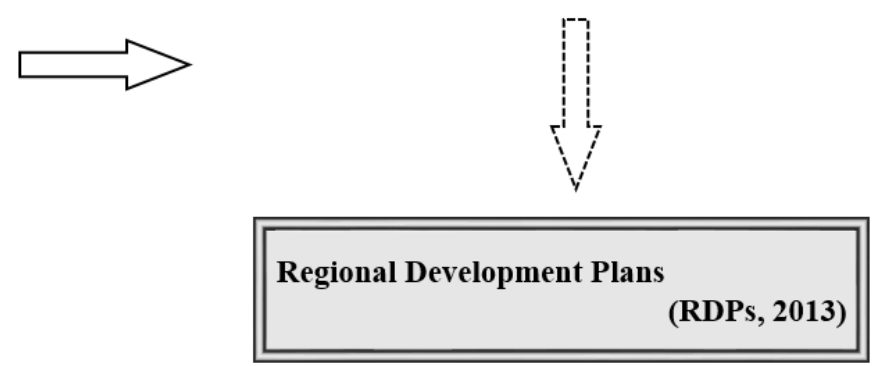

Figure 2: Studied policy documents. 


\subsection{Content analysis}

In order to understand the differences and similarities in how fragmentation is framed in the spatial planning and environmental policy domains, a content analysis was conducted using thematic framework analysis (Ritchie and Lewis, 2003). First, we searched the documents for sentences and paragraphs (called data) regarding the concepts associated with fragmentation and the key fragmentation aspects (Table 1). Second, the data were labeled and coded in terms of the three key fragmentation aspects: 1) biological organization, 2) land cover, and 3) connectivity. These data formed the basis for addressing our research questions.

\subsection{Assessing differences and similarities in framing fragmentation}

We compared the coded data with the statements in Table 1, and assessed their perspective in order to identify the frames and assess their presence in the two policy domains. For example, data addressing habitat fragmentation (often focusing on wetlands or water streams) or the functional connectivity of habitats to facilitate species movement represented a species perspective and were categorized into the species-oriented frame. Data addressing structural connectivity, i.e. connectivity of human designated patches of native vegetation cover, and data formulated as "movement of species assemblage", or data generally formulated as "landscape fragmentation" represented the human-species perspective and were categorized into the pattern-oriented frame. Data addressing the connectivity of human designated patches of land cover to facilitate recreation and human movement provided a human perspective and were categorized into the ecosystem services frame.

The presence of the frames in the two policy domains were quantified and standardized similarly as Kusmanoff et al. (2016). For example, we found 54 data in the environmental policy domain, of which 22 were assigned to the species-oriented frame, 29 to 
the pattern-oriented frame, and three to the ecosystem services frame. These were then standardized by calculating their percentages, i.e. $(22 / 54) * 100$ (i.e. $40,7 \%),(29 / 54) * 100$ (i.e. $53,7 \%$ ), and $(3 / 54) * 100$ (i.e. $5,6 \%$ ), respectively, giving a total sum of $100 \%$ within each policy domain.

Next, we assessed the quality of the framing, i.e. how well the documents frame fragmentation in the two policy domains. To do this, operational definitions of knowledge and value were developed based on four and two criteria, respectively (Table 2). The data were then categorized regarding knowledge, value, and their operational criteria and then compared the number of the fulfilled operational criteria between the two policy domains. The quality of framing was assessed as high if all the criteria were fulfilled.

\subsection{Assessing the type of solutions proposed by the spatial planning and environmental policy domains}

The data were searched for proposed solutions, derived as goals and measures proposed in each document, with these solutions assigned to one of three types - mitigation, avoidance, compensation (Iuell et al., 2003). Mitigation refers to reducing fragmentation to acceptable levels implying adoption and implementation of certain solutions (e.g. construction of wildlife passages) that help to enhance the movement of species and/or humans. Data generally referring to "minimize fragmentation" were categorized as mitigation. Avoidance concerns the protection of a habitat or human designated patches of land cover to prevent fragmentation, thereby increasing the sustainability of any functions. Compensation refers to establishing functional or structural connected habitats or patches of native vegetation cover to replace lost connections (Table 2). In the Czech Republic for example, functional connectivity is addressed in the studied documents by a functional network of significant migration areas, long distance migration corridors, and migration routes for large mammals, i.e. deer, bear, lynx, or moose (Anděl et al., 2010), while structural connectivity is presented 
in the studied documents as the Territorial System of Ecological Stability (TSES) which addresses spatial connected networks of human designated patches of native vegetation cover understood as important for ecological stability (Kubeš, 1996; Mackovčin, 2000). We categorized the solutions addressing TSES as compensation solutions even if the designated patches of native vegetation cover are protected against building development, but not against transportation infrastructure. The preference for the different types of solutions in the two policy domains were assessed by calculating the percentage of each type of solutions within the two policy domains.

\section{Results}

\subsection{Differences and similarities in framing fragmentation in the strategic documents within the spatial planning-and environmental-policy domains}

\subsubsection{Frames in the two policy domains}

The 11 studied documents within the spatial planning- and environmental- policy domains employ all the three frames, with the greatest being the pattern-oriented frame in both domains (Figure 7). The ecosystem services frame was the second most important frame in the spatial planning policy domain, while the species-oriented frame is marginal. This order is reversed in the environmental policy domain.

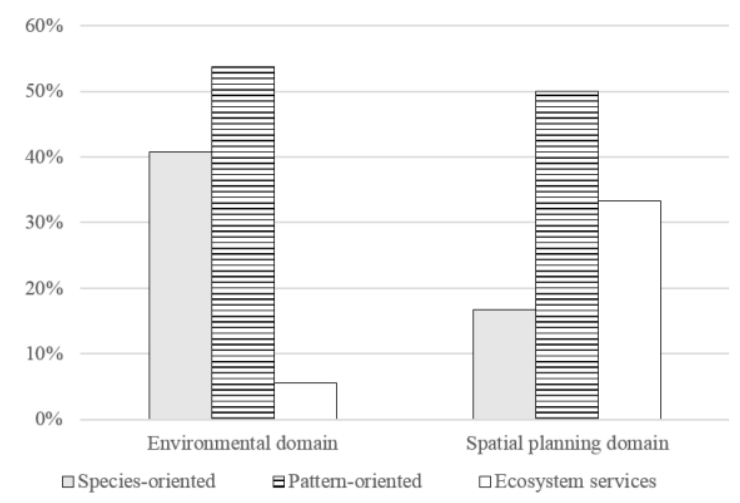


Figure 3: Percentage of the data categorized into the three frames in each policy domain.

\subsubsection{Quality of framing}

Fragmentation is not well framed in the majority of the studied documents since many documents address only very few of the outlined knowledge and values operational criteria (Table 3). While the environmental documents address 4-5 of the 6 operational criteria, most of the spatial planning documents address on average only 3 of them. The documents in both policy domains refer to criteria causes, consequences and responsibility, but none of the studied documents addresses any information about localization (Table 3).

\section{Context}

The criterion context is often a part of the introduction sections of the studied documents. All the documents within the environmental policy domain contain an introduction where they provide context of environmental problems in the Czech Republic and address fragmentation. For example, the National Environmental Policy regards fragmentation as the most serious environmental problem that has to be dealt with in the Czech Republic. On the other hand, most of the studied spatial planning documents do not address the criterion context, but directly formulate solutions.

\section{Definition}

Only two of the studied documents (National Program of Nature and Landscape Protection, National Strategy of Biological Diversity) address the criterion definition and frame fragmentation as a negative process resulting in the loss of land cover patches and affecting population viability. The first document define fragmentation as " $a$ process of dissection of habitat or human designated patches of land cover, but leading also to loss of these patches", while the second document define fragmentation as "a process of dissection 
of continuous landscape by insurmountable barriers that results in low connectivity and isolation of populations that consequently become less viable".

\section{Causes}

The possible causes of fragmentation are identified in all documents (Table 3 ). In the introductions, the environmental documents frame the problem of fragmentation as a complex problem with a broad range of causes, including transport infrastructure, urbanization, water management structures, power plants, tourism, fencing, and agriculture and forestry intensification, all of which have negative impacts. However, the proposed solutions to deal with these causes are connected with transport infrastructure (roads, highways), water management structures (weirs), and urbanization (see below). Urbanization is addressed within the pattern-oriented and ecosystem services frames within both policy domains. Nevertheless, the two policy domains differ in their preference for solutions connected with transport infrastructure and water management structures. While the environmental documents address both transport infrastructure, and water management structures by Species- and Pattern- oriented frames, the spatial planning documents address transport infrastructure by all the three frames and water management structures only by Species oriented frame.

\section{Consequences}

The documents within both policy domains do not frame the "consequences" of fragmentation as species or habitat specific, but only as general statements. The documents refer to consequences either directly as "what the consequences are" (environmental domain only) or through formulation of solutions (both domains). For example, within the speciesoriented frame, the environmental documents refer generally to habitat degradation, decreasing functional connectivity of fragmented habitats, and negative alterations to species populations, or specifically to pollinators, water species, fishes, birds, or big mammals, while 
the spatial planning documents refer only generally to decreasing functional connectivity of water streams and negative effects on the movement of big mammals due to transportation infrastructure. The pattern-oriented frame in the environmental documents refers generally to landscape fragmentation and its negative impact on landscape ecological stability, or mortality of species assemblage, while spatial planning documents address in general "landscape fragmentation", or movement of species assemblages, or humans. On the other hand, the ecosystem services frame in the spatial planning domain is specific regarding shortterm recreation services and connectivity to facilitate movement of humans through traffic networks, while the environmental documents address human well-being in this frame.

\section{Responsibility}

The responsibility criterion varies between the two policy domains. The environmental documents ascribe responsibility to sectoral policies or institutions, and stress the significance of spatial planning on dealing with fragmentation, even if they are not specific in terms of solutions. On the other hand, the spatial planning documents delegate responsibility to regional and local spatial planning authorities according to the Act 183/2006 Coll..

\subsection{Solutions in the environmental and spatial planning policy domains}

The two policy domains do not differ in terms of the types of proposed solutions. Mitigation solutions are the most prominent in both the environmental and spatial planning domains (76 and $68 \%$, respectively), while compensation and avoidance solutions are addressed only seldomly (Figure 4). The mitigation solutions are formulated often to target improvement of functional connectivity of streams, improvement of structural connectivity to facilitate movement of humans by construction of missing links in road networks/ movement of species assemblages through barriers represented by traffic infrastructure, or the mitigation solutions are formulated as general statements to "mitigate or minimize" habitat or landscape 
fragmentation. The compensation solutions address establishment of either functional or structural connectivity in which the latter prevails. For example, the environmental documents formulate solutions addressing functional connectivity as "within the spatial planning process, protect areas where significant migration areas, long distance migration corridors, and migration routes for large mammals are planned to be established". The solutions addressing structural connectivity are formulated by most the documents as "establish the TSES". The spatial planning documents also formulated solutions to connect patches of land cover, i.e. green belts around urbanized areas to facilitate human movement.

Avoidance is the least preferred solution in both domains (Figure 4). Two avoidance solutions are identified in the environmental documents. The first addresses the necessity of protecting existing habitats and migration corridors that sustain functional connectivity for big mammals, a solution which overlaps with the compensation solution, while the second solution addresses the necessity of protecting natural areas against fragmentation when building traffic infrastructure. While the first solution is not offered within the spatial planning policy domain, the latter solution is integrated into one RDP. The other avoidance solutions within the spatial planning policy domain address protection of human designated patches of land cover near urban areas to sustain human well-being and movement.

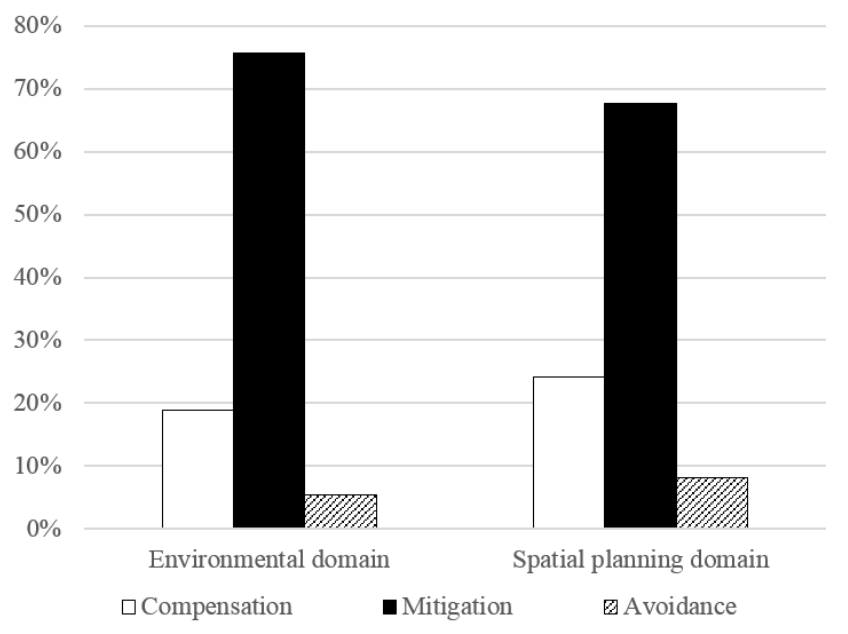


Figure 4: Percentage of the data categorized as types of solutions per the each policy domain.

\section{Discussion}

Framing fragmentation as a policy problem is desirable (Anděl et al., 2009), although it is a challenge because complex issues such as fragmentation are hard to grasp by policies considering that policies are influenced and shaped by different knowledge and values not only by scientific research (Pullin et al., 2009; Veselý and Nekola, 2007). Our study shows differences and similarities in how fragmentation is framed and the types of proposed solutions to deal with fragmentation in the strategic documents within the spatial planningand environmental- policy domains. Both policy domains employ species-oriented, patternoriented, and ecosystem services frames and mention mitigation, compensation and avoidance solutions. However, the domains differ in the prevalence of the frames, their quality, and preferred solutions.

\subsection{Differences and similarities in framing fragmentation}

We observed a dominance of the pattern-oriented frame in the strategic policy documents in the both policy domains in the Czech Republic. There may be several reasons for this similarity in how fragmentation is framed. First is that most of the studied policy documents address structural connectivity, i.e. connectivity of human designated patches of native vegetation, rather than the functional connectivity of habitats. This is likely due to the fact that planning of structural connectivity, presented in the Czech Republic under the TSES concept, has a long tradition in policy and legislation (Kubeš, 1996), being supported by the Act on Nature and Landscape Protection, No. 114/1992 (the Czech National Council, 1992), and the Act on Spatial Planning, No. 183/2006 (the Parliament of the Czech Republic, 2006). The situation in Slovakia is very similar to that in the Czech Republic, where structural 
connectivity is also supported by legislation (Izakovičová, 2012), or for example in the Netherlands (Van Der Windt and Swart, 2008). Functional connectivity is supported by legislation for example in England, Northern Ireland, Scotland and Wales (Kettunen et al., 2007). Nevertheless, low support for functional connectivity is evident in many other European strategies and spatial planning documents (Brajanoska et al., 2009; Grădinaru and Hersperger, 2018). Second, the emphasis on the pattern-oriented frame may be due to the general formulation of statements addressing fragmentation, which is evident in both policy domains. In this case, most of the data are framed generally as "minimize fragmentation", i.e. they are neither species nor habitat specific. Turnhout et al. (2008) pointed out that using general statements signals a low awareness of environmental policies and a tendency to use vague concepts. Vague concepts are easily accepted because they are flexible so to be used by people with different backgrounds, including politicians, scientists, as well as practitioners (Van Der Windt and Swart, 2008). Third, the species-oriented frame needs to be supported by scientific knowledge about species specific demands on habitat patches, their size, quality and connectivity, either in space and time (Auffret et al., 2015; Uezu et al., 2005; Zetterberg et al., 2010) and these information has to be well framed for policy and management purposes. The low support for functional connectivity in policy documents points to its challenging integration in policy documents, because scientists need to better address the importance of different land cover patches for movement of single species, and develop better mathematical models for assessing functional connectivity (Zetterberg et al., 2010). Policy documents have to find balance between all the studied frames (i.e. both the functional and structural connectivity) in context of the whole landscape with respect to specific animal and plant species that may prioritize either structural or functional connectivity (Auffret et al., 2015; Uezu et al., 2005; Zetterberg et al., 2010). 
The fact that the species-oriented frame is employed more by the environmental policy domain while the ecosystem services frame is a more common feature of the spatial planning policy domain can be explained by the interest orientation of the policy institutions within these policy domains. This difference could reflect a focus on different values, respectively eco-centric ones in the case of the environmental domain and an anthropocentric values in the case of the spatial planning domain. While the environmental documents focus on environmental quality and species needs, for example their viability, abundance, diversity, movement facilities, etc., the spatial planning documents focus on human needs and prioritize human well-being, for example infrastructure development, housing, recreation, etc.

Our assessment of the quality of framing show differences between the spatial planning and environmental policy domains, in which the spatial planning documents fulfill only a few of the operational criteria of the framing elements. The above-described tendency to formulate general statements addressing fragmentation lends credence to the view that the problem of fragmentation is not well framed, especially within the spatial planning documents. The spatial planning documents do not describe the context, do not provide any definition of fragmentation, nor provide information about the local magnitude of fragmentation, they reduce the complexity of the problem of fragmentation by noting only a few causes, and neglect species-specific consequences and solutions. This missing of operational criteria in the strategic policy documents signal a low institutional knowledge about fragmentation. The low quality of the frames together with using general formulations means that fragmentation is understood as something like an axiom, which might be counterproductive when looking for solutions. Nevertheless, differences between policy domains in framing environmental issues have been identified in Europe. For example, Niţă et al. (Niţă et al., 2015) highlighted the differences in the use of landscape concepts by Romanian and Swiss experts in conducting Environmental Impact Assessment. Good 
environmental framing has to be supported by well-defined concepts, communications between scientists and non-scientists, as well as relevant knowledge and values (Van Der Windt and Swart, 2008).

\subsection{Unbalanced proposal of mitigation, avoidance and compensation solutions to fragmentation}

Protection of valuable non-fragmented habitats and connectivity restoration are important for mitigating and adapting to fragmentation (Donaldson et al., 2017). Thus, we expected a balance between all the three solution types, avoidance, compensation and mitigation. However, mitigation is the most common type of solution in the strategic policy documents of both spatial planning and environmental policy domains, while the compensation and especially avoidance solutions are under-represented. This bias towards mitigation solutions may be due to a) a focus of solutions on the movement of biological organizations through insurmountable barriers created by human activities that cause fragmentation, and b) the formulation of general solutions, for example "minimize fragmentation". Moreover, this focus on mitigation can be interpreted as a result of policy makers seeing fragmentation of habitats and landscapes as a somehow obvious consequence of infrastructure development (e.g. of roads). Thus, policy documents focus on mitigation solutions that will remedy the negative consequences. Avoidance and compensation solutions are important as they focus on the protection and establishment of valuable non-fragmented structural or functional patches of native vegetation or habitats, and thus should be prioritized (Jaeger and Madrinan, 2011) within a policy document. However, these solutions are rarely formulated in policy documents likely because of their possible conflict with human demands on land (Donaldson 2017), and that the establishment and management of new patches are quite time, land and cost demanding. Thus, support of avoidance and compensation solutions may be a challenge for spatial planning. To support these solutions, policy institutions have to better frame 
fragmentation and be specific in formulating solutions in strategic policy documents.

Although the presence of remedy solutions in the Czech strategic documents is a positive trend that denotes an increasing interest in fragmentation, as compared to previous decades (Semančíková et al., 2008), the documents do not address limits for fragmentation (e.g. maximal acceptable thresholds). Thus, we do not know which landscapes are overly fragmented and what is acceptable from the strategies, although the European Environmental Agency provides an indicator for assessing landscape fragmentation at the NUTS level. For example, in Germany, the German Federal Environmental Agency monitors fragmentation and defines limits for fragmentation that are used in landscape planning (Jaeger et al., 2008). On the other hand, although indicator for assessing landscape fragmentation is recognized between experts, its use for landscape planning and environmental impact assessment is still rather challenging (Jaeger et al., 2008; Niţă et al., 2015).

Our study shows that institutions from both policy domains frame fragmentation as a negative environmental policy problem, which is framed from various perspectives and focuses on different aspects. Nevertheless, the quality of framing is crucial for formulating species specific and spatially explicit solutions.

\section{Conclusions}

Our study shows that fragmentation is a broad and complex issue related to a variety of driving factors, consequences, and solutions. Fragmentation is framed as a policy issue within both the spatial planning and environmental policy domains. However, considerable gaps are evident in relation to the framing of fragmentation within the policy domains. The results show that strategic documents tend to handle the complexity of the fragmentation problem by using general statements and formulating general goals. This conclusion is supported by 1) the fact that pattern-oriented frame and mitigation solutions are the most prominent, and 2) 
the low quality in framing fragmentation in most of the studied documents. We expect similar results to be found in other countries, as the experts involved in policy making can have different backgrounds and knowledge of landscape concepts. Based on our results, we recommend better framing of fragmentation in strategic policy documents, based on welldefined concepts and transdisciplinary communication among scientists, politicians and practitioners. Policy documents must better address the knowledge and values for improving the quality of framing fragmentation. Providing a definition of fragmentation, a contextual description of the state and development of fragmentation, spatially explicit information about the magnitude of fragmentation, causes related to its consequences, and information about responsible institutions, authorities, etc. should help to formulate specific and spatially explicit solutions. For example, the European Union, through Agri-Environmental schemes, provides subsidies supporting the maintenance of landscape features, conservation of highvalue habitats and establishment of small semi-natural habitats (e.g. road verges, hedgerows) that can effectively mitigate the negative consequences of fragmentation. In this case, a clear framing could assure a successful implementation of avoidance and mitigation solutions as well as clarify the specific conditions for offering compensation measures. Furthermore, spatial planning documents as legal binding documents need to greatly improve the quality of framing fragmentation, find a balance between the species, human-species and human perspectives, and address more avoidance and compensation solutions.

\section{Acknowledgements}




\section{Literature}

Anděl, P., Andreas, M., Gorčicová, I., Hlaváč, V., Mináriková, T., Romportl, D., Strnad, M., Zieglerová, a, 2009. Koncepce ochrany migračních koridorů velkých savců a územní systém ekologické stability.

Anděl, P., Mináriková, T., Andreas, M., 2010. Ochrana průchodnosti krajiny pro velké savce. Evernia, Liberec, Liberec.

Auffret, A.G., Plue, J., Cousins, S.A.O., 2015. The spatial and temporal components of functional connectivity in fragmented landscapes. Ambio 44, 51-59. https://doi.org/10.1007/s13280-0140588-6

Baguette, M., Van Dyck, H., 2007. Landscape connectivity and animal behavior: functional grain as a key determinant for dispersal. Landsc. Ecol. 22, 1117-1129. https://doi.org/10.1007/s10980-0079108-4

Bardwell, L. V., 1991. Problem-Framing: A Perspective on Environmental Problem-Solving. Environ. Manage. 15, 603-612.

Bennet, A.F., Saunders, A., 2010. Habitat fragmentation and landscape change, in: Sodhi, N.S., Ehrlich Paul, R. (Eds.), Conservation Biology for All. Oxford University Press, Oxford, pp. 88105 .

Brajanoska, R., Čivić, K., Hristovski, S., Jones-Walters, Levkov, Z., Lj, M., Melovski, D., Velevski, M., 2009. Background document on Ecological Networks. Skopje, Republic of Macedonia.

CENIA, 2013. Report on the state of the environment of the Czech Republic. Praha.

Daugbjerg, S.B., Kahlmeier, S., Racioppi, F., Martin-Diener, E., Martin, B., Oja, P., Bull, F., 2009. Promotion of Physical Activity in the European Region: Content Analysis of 27 National Policy Documents. J. Phys. Act. Heal. 6, 805-817.

Deák, B., Valkó, O., Török, P., Kelemen, A., Bede, Á., Csathó, A.I., Tóthmérész, B., 2018. Landscape and habitat filters jointly drive richness and abundance of specialist plants in terrestrial habitat islands. Landsc. Ecol. 33, 1117-1132. https://doi.org/10.1007/s10980-018-0660-x

Di Giulio, M., Holderegger, R., Tobias, S., 2009. Effects of habitat and landscape fragmentation on humans and biodiversity in densely populated landscapes. J. Environ. Manage. 90, 2959-2968. https://doi.org/10.1016/j.jenvman.2009.05.002

Donaldson, L., Wilson, R.J., Maclean, I.M.D., 2017. Old concepts, new challenges: adapting landscape-scale conservation to the twenty-first century. Biodivers. Conserv. 26, 527-552. https://doi.org/10.1007/s10531-016-1257-9

Ebbin, S.A., 2011. The Problem with Problem Definition: Mapping the Discursive Terrain of Conservation in Two Pacific Salmon Management Regimes. Soc. Nat. Resour. 24, 148-164. https://doi.org/10.1080/08941920903468639

EEA, 2011. Landscape fragmentation in Europe. Joint EEA-FOEN Report No 2/2011. Copenhagen.

Fahrig, L., 2017. Ecological Responses to Habitat Fragmentation Per Se. Annu. Rev. Ecol. Evol. Syst. https://doi.org/10.1146/annurev-ecolsys-110316-022612

Fahrig, L., 2003. Effects of habitat fragmentation on biodiversity. Annu. Rev. Ecol. E volution Syst. 34, 487-515. https://doi.org/10.1146/annurev.ecolsys.34.011802.132419

Fischer, J., Lindenmayer, D.B., 2007. Landscape modification and habitat fragmentation: a synthesis. Glob. Ecol. Biogeogr. 16, 265-280. https://doi.org/10.1111/j.1466-8238.2006.00287.x

Grădinaru, S.R., Hersperger, A.M., 2018. Green infrastructure in strategic spatial plans: Evidence 
from European urban regions. Urban For. Urban Green.

https://doi.org/10.1016/j.ufug.2018.04.018

Hadley, A.S., Betts, M.G., 2016. Refocusing Habitat Fragmentation Research Using Lessons from the Last Decade. Curr. Landsc. Ecol. Reports 1, 55-66. https://doi.org/10.1007/s40823-016-0007-8

Haila, Y., 2002. A Conceptual Genealogy of Fragmentation Research : From Island Biogeography to Landscape Ecology Yrjö Haila A CONCEPTUAL GENEALOGY OF FRAGMENTATION RESEARCH : FROM ISLAND BIOGEOGRAPHY TO LANDSCAPE ECOLOGY. Ecol. Soc. Am. 12, 321-334.

Haug, C., Rayner, T., Jordan, A., Hildingsson, R., Stripple, J., Monni, S., Huitema, D., Massey, E., van Asselt, H., Berkhout, F., 2010. Navigating the dilemmas of climate policy in Europe: evidence from policy evaluation studies. Clim. Change 101, 427-445. https://doi.org/10.1007/s10584-009-9682-3

Iuell, B., Bekker, G.J., Cuperus, R., Dufek, J., Fry, G., Hlaváč, V., Keller, V., Rosell, C., 2003. Wildlife and Traffic: A European Handbook for Identifying Conflicts and Designing Solutions. Luxembourg.

Izakovičová, Z., 2012. Landscape-Ecological Plan as the Basic Tool for Sustainable Land Use 7, 8-17.

Jaeger, A.G., Madrinan, F.L., 2011. Landscape Fragmentation in Europe, Ilpoe.Uni-Stuttgart.De. https://doi.org/10.2800/78322

Jaeger, J. a G., Bertiller, R., Schwick, C., Müller, K., Steinmeier, C., Ewald, K.C., Ghazoul, J., 2008. Implementing Landscape Fragmentation as an Indicator in the Swiss Monitoring System of Sustainable Development (Monet). J. Environ. Manage. https://doi.org/10.1016/j.jenvman.2007.03.043

Karlsson-Vinkhuyzen, S., Kok, M.T.J., Visseren-Hamakers, I.J., Termeer, C.J.A.M., 2017. Mainstreaming biodiversity in economic sectors: An analytical framework. Biol. Conserv. 210, 145-156. https://doi.org/10.1016/j.biocon.2017.03.029

Kettunen, M., Terry, A., Tucker, G., Jones, A., 2007. Guidance on the maintenance of landscape connectivity features of major importance for wild flora and fauna - Guidance on the implementation of Article 3 of the Birds Directive (79/409/EEC) and Article 10 of the Habitats Directive (92/43/EEC). Brussels.

Knaggård, Å., 2015. The Multiple Streams Framework and the problem broker. Eur. J. Polit. Res. 54, 450-465. https://doi.org/10.1111/1475-6765.12097

Kubeš, J., 1996. Biocentres and corridors in a cultural landscape. A critical assessment of the 'territorial system of ecological stability.' Landsc. Urban Plan. 35, 231-240. https://doi.org/10.1016/S0169-2046(96)00321-0

Kusmanoff, A.M., Hardy, M.J., Fidler, F., Maffey, G., Raymond, C., Reed, M.S., Fitzsimons, J.A., Bekessy, S.A., 2016. Framing the private land conservation conversation: Strategic framing of the benefits of conservation participation could increase landholder engagement. Environ. Sci. Policy 61, 124-128. https://doi.org/10.1016/j.envsci.2016.03.016

Lindenmayer, D.B., Fischer, J., 2007. Tackling the habitat fragmentation panchreston. Trends Ecol. Evol. 22, 127-132. https://doi.org/10.1016/j.tree.2006.11.006

Loomis, J., G, H., Helfand, G., 2003. Environmental policy analysis for decision making, Environmental Impact Assessment Review. Kluwer Academic Publisher, New York. https://doi.org/10.1016/S0195-9255(02)00014-8

Loorbach, D., 2010. Transition management for sustainable development: A prescriptive, complexitybased governance framework. Governance 23, 161-183. https://doi.org/10.1111/j.1468- 
0491.2009.01471.x

Mackovčin, P., 2000. A multi-level ecological network in the Czech Republic: Implementating the Territorial System of Ecological Stability. GeoJournal 51, 211-220. https://doi.org/10.1023/A:1017518529210

McIntyre, S., Hobbs, R., 1999. A Framework for Conceptualizing Human Effects on Landscapes and Its Relevance to Management and Research Models. Conserv. Biol. 13, 1282-1292. https://doi.org/10.1046/j.1523-1739.1999.97509.x

Michaels, S., 2009. Matching knowledge brokering strategies to environmental policy problems and settings. Environ. Sci. Policy 12, 994-1011. https://doi.org/10.1016/j.envsci.2009.05.002

Mitchell, M.G.E., Suarez-Castro, A.F., Martinez-Harms, M., Maron, M., McAlpine, C., Gaston, K.J., Johansen, K., Rhodes, J.R., 2015. Reframing landscape fragmentation's effects on ecosystem services. Trends Ecol. Evol. 30, 190-198. https://doi.org/10.1016/j.tree.2015.01.011

MoRD, 2015. National Planning Policy (NPP). the Czech Republic.

Moschitz, H., 2018. Where is urban food policy in Switzerland? A frame analysis. Int. Plan. Stud. 23, 180-194. https://doi.org/10.1080/13563475.2017.1389644

Nisbet, M.C., 2009. Communicating Climate Change: Why Frames Matter for Public Engagement. Environ. Sci. Policy Sustain. Dev. 51, 12-23.

Niţă, A., Buttler, A., Rozylowicz, L., Pătru-Stupariu, I., 2015. Perception and use of landscape concepts in the procedure of Environmental Impact Assessment: Case study-Switzerland and Romania. Land use policy 44, 145-152. https://doi.org/10.1016/j.landusepol.2014.12.006

Pullin, A.S., Báldi, A., Can, O.E., Dieterich, M., Kati, V., Livoreil, B., LÖvei, G., Mihok, B., Nevin, O., Selva, N., Sousa-Pinto, I., 2009. Conservation Focus on Europe: Major Conservation Policy Issues That Need to Be Informed by Conservation Science. Conserv. Biol. 23, 818-824. https://doi.org/10.1111/j.1523-1739.2009.01283.x

Resasco, J., Bruna, E.M., Haddad, N.M., Banks-Leite, C., Margules, C.R., 2017. The contribution of theory and experiments to conservation in fragmented landscapes. Ecography (Cop.). 40, 109118. https://doi.org/10.1111/ecog.02546

Ritchie, J., Lewis, J., 2003. Qualitative research practice, 1st ed. SAGE Publications Ltd, London.

Secretariat of the CBD, 2005. Handbook of the Convention on Biological Diversity Including its Cartagena Protocol on Biosafety, 3rd ed. Montreal, Canada.

Semančíková, E., Dvořáková-Líšková, Z., Holcová, V., 2008. How strategic planning deals with spatial landscape problems?, in: Kabrda, J., Bičík, J. (Eds.), Man in the Landscape across Frontiers: Landscape and Land Use Change in Central European Border Regions. Faculty of Science, Charles University in Prague, Czech Republic., Prague, pp. 153-163.

the Czech National Council, 1992. Act No. 114/1992 Coll., on the Conservation of Nature and Landscape, on the Conservation of Nature and Landscape. Czech Republic.

the Parliament of the Czech Republic, 2006. Act No. 183/2006 Coll., on Town and Country Planning and Building, on Town and Country Planning and Building. Czech Republic.

Turnhout, E., Hisschemöller, M., Eijsackers, H., 2008. Science in Wadden Sea policy: from accommodation to advocacy. Environ. Sci. Policy 11, 227-239. https://doi.org/10.1016/j.envsci.2007.07.004

Uezu, A., Metzger, J.P., Vielliard, J.M.E., 2005. Effects of structural and functional connectivity and patch size on the abundance of seven Atlantic Forest bird species. Biol. Conserv. 123, 507-519. https://doi.org/10.1016/j.biocon.2005.01.001 
Van Der Windt, H.J., Swart, J. a a, 2008. Ecological corridors, connecting science and politics: The case of the Green River in the Netherlands. J. Appl. Ecol. 45, 124-132. https://doi.org/10.1111/j.1365-2664.2007.01404.x

Veselý, A., Nekola, M., 2007. Analýza a tvorba veřejných politik. Př́stupy, metody a praxe, 1. ed. Sociologické nakladatelství (SLON), Praha.

Zetterberg, A., Mörtberg, U.M., Balfors, B., 2010. Making graph theory operational for landscape ecological assessments, planning, and design. Landsc. Urban Plan. 95, 181-191. https://doi.org/10.1016/j.landurbplan.2010.01.002 
Table 1: Frames and their associated concepts.

\begin{tabular}{|c|c|c|c|}
\hline & $\begin{array}{l}\text { species-oriented } \\
\text { frame }\end{array}$ & $\begin{array}{l}\text { pattern-oriented } \\
\text { frame }\end{array}$ & $\begin{array}{l}\text { ecosystem services } \\
\text { frame }\end{array}$ \\
\hline Perspective: & Species & Human-species & Human \\
\hline \multicolumn{4}{|c|}{ Key fragmentation aspects: } \\
\hline $\begin{array}{l}\text { - Biological } \\
\text { organization }\end{array}$ & Single species & Species assemblage & Human \\
\hline - Land cover & $\begin{array}{l}\text { Habitat } \\
\text { fragmentation, i.e. } \\
\text { fragmentation of } \\
\text { patches of habitat }\end{array}$ & $\begin{array}{c}\text { Landscape } \\
\text { fragmentation, i.e. } \\
\text { fragmentation of } \\
\text { human designated } \\
\text { patches of land cover } \\
\text { (native vegetation } \\
\text { cover) }\end{array}$ & $\begin{array}{c}\text { Landscape } \\
\text { fragmentation, i.e. } \\
\text { fragmentation of } \\
\text { human designated } \\
\text { patches of land cover } \\
\text { (human modified } \\
\text { vegetation cover) }\end{array}$ \\
\hline - Connectivity & $\begin{array}{c}\text { Functional, i.e. } \\
\text { connectivity of } \\
\text { habitats to facilitate } \\
\text { movement of single } \\
\text { species }\end{array}$ & $\begin{array}{c}\text { Structural, i.e. } \\
\text { connectivity of patches } \\
\text { of native vegetation } \\
\text { cover to facilitate } \\
\text { movement of species } \\
\text { assemblage }\end{array}$ & $\begin{array}{c}\text { Connectivity to } \\
\text { facilitate movement of } \\
\text { humans }\end{array}$ \\
\hline
\end{tabular}


Table 2: Framing elements and criteria operationalizing them.

Knowledge Information about the state of the problem is seen as the most important element of framing.

Explanation of the problem of fragmentation and contextual description

Context of land cover patches that are fragmented, as well as a state and development of fragmentation.

Definition Providing definition of the concept "fragmentation".

Causes Address the causes of fragmentation.

Localization Spatially explicit information about magnitude of fragmentation.

Values Values are linked to explanations regarding why we should care about a problem, what is threatened, what should be protected and also who is responsible for solutions.

Consequences Address what or who is threatened by fragmentation, as well as why we should care about it.

Responsibility Institutions, people, etc. responsible with addressing a problem with fragmentation. 
Table 3: Quality of framing.

Framing elements and criteria operationalizing them
Number of documents addressing criteria within policy domains 


\section{List of Figure captions:}

Figure 5: The key fragmentation aspects viewed from different perspectives refer to different knowledge, values and results to different frames.

Figure 6: Studied policy documents.

Figure 7: Percentage of the data categorized into the three frames in each policy domain.

Figure 8: Percentage of the data categorized as types of solutions per the each policy domain. 